\title{
SULPHATE ATTACK IN SLAG-BLENDED CEMENTITIOUS MATERIALS HYDRATED WITH SODIUM SULPHATE
}

\author{
Li Chuang ${ }^{1}$, Tomohiro Kajio ${ }^{1}$, Eiji Owaki ${ }^{2}$, Yuka Morinaga ${ }^{1}$, Yogarajah Elakeswaran ${ }^{1}$, \\ and Toyoharu Nawa ${ }^{3}$
}

${ }^{1}$ Division of Sustainable Resources Engineering, Faculty of Engineering, Hokkaido

University, Kita 13, Nishi 8, Kita-ku, Sapporo, 060-8628, Japan

${ }^{2}$ Civil Structure and Material Research Section, Civil Engineering Research Institute

Technology Centre, Taisei Corporation, Japan

${ }^{3}$ Hokkaido University, Kita 8, Nishi 5, Kita-ku, Sapporo, 060-0808, Japan

Corresponding author: Elakneswaran, Y., email: elakneswaran@eng.hokudai.ac.jp

\begin{abstract}
Deterioration of cementitious materials co-hydrating with highly concentrated sodium sulphate is a major durability problem for the use of the materials in low- or intermediatelevel nuclear waste repositories. The sulphate attack is a physicochemical interaction of sulphate ions and cement matrix. Understanding the underlaying mechanisms and influencing factors are important to evaluate the long-term performance of the materials in the nuclear waste repositories. In this study, Portland cement and slag-blended cementitious materials in which the cement is replaced by $42 \%$ of slag were hydrated $13 \%$ of $\mathrm{Na}_{2} \mathrm{SO}_{4}$ by weight. The hydrated samples having diameter between $2.38 \mathrm{~mm}$ and 4.75 $\mathrm{mm}$ were immersed in water, sodium and magnesium sulphate solution to evaluate its degradation. Solid phases in the samples before and after the exposure were quantified by XRD/Rietveld analysis and the results were compared with thermodynamic equilibrium model. The model prediction agrees with experimental data except U-phase and ettringite. The experimental results show that the U-phase is not stable in exposure solution and it is changed to ettringite, but the model could not predict it. The effect of solution composition, the type of associated cation, and the presence of slag and its replacement ratio on the experimental and simulation results were discussed.
\end{abstract}

Keywords: Cementitious material, slag, Portland cement.

\section{INTRODUCTION}

Cementitious materials have been used in low- or intermediate-level nuclear waste repositories. The liquid nuclear waste is evaporated before solidifying with cementitious materials to reduce its volume, leading high concentration of salts such as sodium sulphate in the waste [Li 1996]. Furthermore, sulfuric acid has been used to remove the precipitates formed in the pipes of cooling water, which may produce very high concentration of sodium sulphate up to $25 \%$ by weight in the low-level radioactive waste [Owaki 2012]. Solidification of highly concentrated sodium sulphate nuclear waste into cementitious materials may deteriorate the materials and damage the repositories due to physical and chemical interaction of sodium sulphate with cement hydrates.

The chemical interaction of sulphate with cement hydrates forms expansive sulphate bearing products such as ettringite and gypsum while the sodium sulphate crystallisation 
is the main form of physical sulphate attack in cementitious materials. Only a few studies have reported about the effect of high concentration of sodium sulphate on hydrating cementitious materials [Jean-Baptiste 2015; Li 1996]. Our recent modelling study evaluates the long-term performance of hydrating Portland cement in sodium sulphate solution as well as its performance against to external sulphate attack [Elakneswaran 2018]. However, the modelling study did not consider the U-phase $\left[(\mathrm{CaO})_{4}\left(\mathrm{Al}_{2} \mathrm{O}_{3}\right)_{0.9}\left(\mathrm{SO}_{3}\right)_{1.1}\left(\mathrm{Na}_{2} \mathrm{O}\right)_{0.5}: 16 \mathrm{H}_{2} \mathrm{O}\right]$ which could form in a very high concentration of sodium sulphate solution and it may cause deterioration to the solidified material through its formation or transformation to ettringite. The stability of U-phase in cementitious materials and its phase change to ettringite are still not understood well due to limited number of studies. Moreover, the conditions which may induce to form U-phase in cementitious material under external sulphate attack are not known yet. Therefore, in this study, the stability of U-phase and other hydration products formed in Portland cement and slag-blended cement hydrated in sodium sulphate solution is evaluated when the hydration products exposed to water, sodium and magnesium sulphate solution with different concentration. The phase changes as the hydrates exposed to water or sulphate solution was quantitatively determined by X-ray diffraction (XRD) and Rietveld analysis and the results were verified with thermodynamic model.

\section{MATERIALS AND METHODS}

\section{Materials and Sample Preparation}

White Portland Cement(WPC) and Blast Furnace Slag(BFS) were used in this study. Chemical composition of WPC and BFS are given in Table 1. Three series of specimens as given in Table 2 were prepared: WPC was mixed with either water or $13 \%$ of $\mathrm{Na}_{2} \mathrm{SO}_{4}$ and slag-blended WPC (42\% of slag replacement) mixed with $13 \%$ of $\mathrm{Na}_{2} \mathrm{SO}_{4}$. All the specimens were prepared at a fixed water to binder ratio of 0.6 and sealed cured at $50{ }^{\circ} \mathrm{C}$ for 28 days. The temperature of $50{ }^{\circ} \mathrm{C}$ was adopted to form U-phase during the hydration of cement with $\mathrm{Na}_{2} \mathrm{SO}_{4}$. After the curing, the specimens were crushed and sieved to provide samples of diameter between $2.38 \mathrm{~mm}$ and $4.75 \mathrm{~mm}$. Around $25 \mathrm{~g}$ of the sample was immersed into known sulphate concentration of $500 \mathrm{~mL}$ solution for a period of 3, 7, and 28 days. The adopted sulphate solutions were pure water, 100 and $1300 \mathrm{mmol} / \mathrm{L}$ of $\mathrm{Na}_{2} \mathrm{SO}_{4}$ and 100 and $1300 \mathrm{mmol} / \mathrm{L}$ of $\mathrm{MgSO}_{4}$. Once the specified exposure period was completed, the samples were ground, and the powders were used for X-ray diffraction (XRD) and Rietveld analysis to determine the phases and its composition. To quantitatively determine the U-phase, the known amount of synthesised U-phase was mixed with the hydrated samples and XRD patterns were obtained to draw the calibration curve for the intensity of U-phase. The amount of U-phase in hydrates was calculated by the ratio of intensity of XRD pattern.

Table 1. Chemical composition of WPC and BFS

\begin{tabular}{|c|c|c|c|c|c|c|c|c|c|}
\hline Mass\% & $\mathrm{SiO}_{2}$ & $\mathrm{Al}_{2} \mathrm{O}_{3}$ & $\mathrm{Fe}_{2} \mathrm{O}_{3}$ & $\mathrm{CaO}$ & $\mathrm{MgO}$ & $\mathrm{SO}_{3}$ & $\mathrm{Na}_{2} \mathrm{O}$ & $\mathrm{K}_{2} \mathrm{O}$ & $\mathrm{P}_{2} \mathrm{O}_{2}$ \\
\hline WPC & 20.8 & 5.4 & 0.2 & 67.5 & 1.56 & 2.78 & 0.6 & 0.36 & 0.44 \\
\hline BFS & 34.03 & 14.36 & 0.83 & 43.28 & 6.51 & 0 & 0.8 & 0.31 & 0.46 \\
\hline
\end{tabular}

Table 2. Experimental outline

\begin{tabular}{|c|c|c|c|c|c|}
\hline & Cement & $\begin{array}{c}\text { Water/Binder } \\
\text { ratio }\end{array}$ & $\begin{array}{c}\text { Slag } \\
\text { replacement }\end{array}$ & Mixing solution & $\begin{array}{c}\text { Curing } \\
\text { condition }\end{array}$ \\
\hline Series 1 & WPC & 0.6 & 0 & $\begin{array}{c}13 \% \mathrm{Na}_{2} \mathrm{SO}_{4} \\
\text { solution }\end{array}$ & 28 days, $50^{\circ} \mathrm{C}$ \\
\hline Series 2 & WPC & 0.6 & $42 \%$ & $\begin{array}{c}13 \% \mathrm{Na}_{2} \mathrm{SO}_{4} \\
\text { solution }\end{array}$ & 28 days, $50^{\circ} \mathrm{C}$ \\
\hline
\end{tabular}




\begin{tabular}{|l|c|c|c|c|c|}
\hline Series 3 & WPC & 0.6 & 0 & Pure water & 28 days, $50^{\circ} \mathrm{C}$ \\
\hline
\end{tabular}

\section{Modelling Approach}

The geochemical code PHREEQC was employed in this study to carry out speciation and thermodynamic equilibrium calculations. An integrated model that couples PHREEQC and Excel, developed in a previous study (Elakneswaran 2016), was used to predict the composition of solid phases. The thermodynamic properties for various phases and minerals found in the cement system were collected from CEMDATA07 [Lothenbach 2008] and others [Myers 2014], and the data were converted into a format suitable for PHREEQC. The converted data (reported in Reference [Elakneswaran 2018]), together with the PHREEQC default thermodynamic database [Parkhust 1999], were used for every calculation. The thermodynamic equilibrium constant for the U-phase formation, given in Eq. (1) and (2) (Kajio 2018).

$$
\begin{gathered}
(\mathrm{CaO})_{4}\left(\mathrm{Al}_{2} \mathrm{O}_{3}\right)\left(\mathrm{SO}_{3}\right) 1.5\left(\mathrm{Na}_{2} \mathrm{O}\right) 0.75: 16 \mathrm{H}_{2} \mathrm{O}+12.5 \mathrm{H}^{+} \\
=4 \mathrm{Ca}^{2+}+2 \mathrm{Al}^{3+}+1.5 \mathrm{Na}^{+}+1.5 \mathrm{SO}_{4}^{2-}+22.25 \mathrm{H}_{2} \mathrm{O} \\
\log \mathrm{K}=68.56
\end{gathered}
$$

The hydration reaction of clinker minerals in sodium sulphate solution were determined by XRD/Rietveld analysis and given to the hydration model as input parameters to calculate the solid products at 28 days of hydration. To simulate the interaction of exposure sulphate solution with the hydration products, the phase-equilibrium reaction between cement hydrates at 28 days of hydration and the sulphate solution were considered. The simulation results were compared with experimental data of 28 days of exposure because the exposure period of 3 or 7 days may not reach the equilibrium.

\section{RESULTS AND DISCUSSION}

\section{Influence of Sulphate Solution on the Stability of Hydration Products}

The XRD/Rietveld analysis was performed for the samples given in Table 2 after 28 days of hydration, and the results are shown in Fig. 1. In addition to main hydrates of calcium silicate hydrate (C-S-H) (given as amorphous) and portlandite, the U-phase was produced in both WPC and slag-blended WPC hydrated in sodium sulphate solution. A partial replacement of WPC by slag increases the U-phase formation.

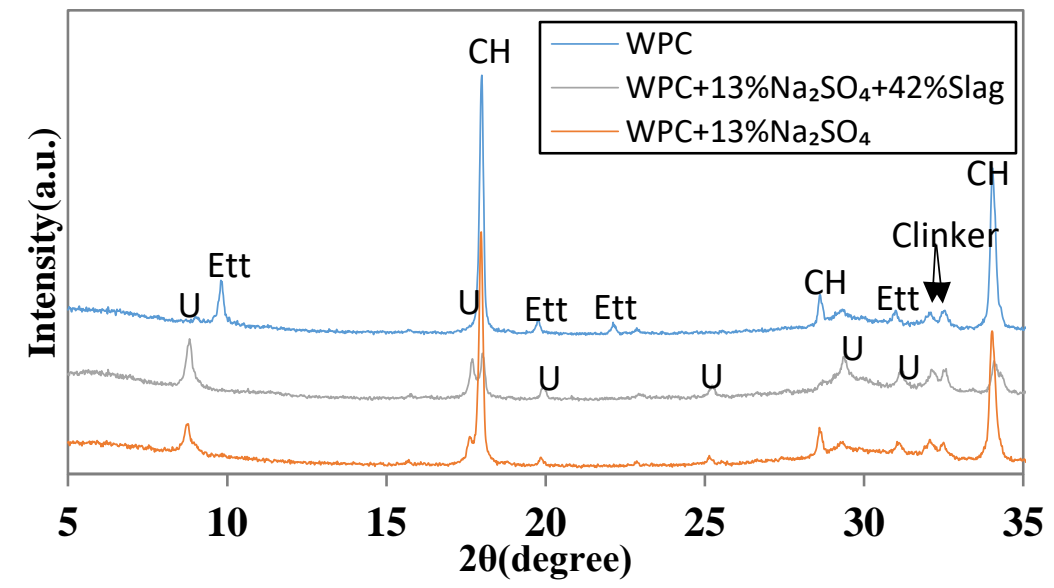

Fig. 1. XRD patterns of hydrated and slag-blended WPC in water and $13 \%$ of $\mathrm{Na}_{2} \mathrm{SO}_{4}$

The phase changes in WPC (Series 1), which was hydrated in $13 \%$ of $\mathrm{Na}_{2} \mathrm{SO}_{4}$ solution for 
28 days, exposed to various sulphate solution for a period of 3, 7, and 28 days are shown in Fig. 2. The type of solution and its concentration affect the stability of U-phase and its transformation to ettringite. The exposure solution of water or $\mathrm{MgSO}_{4}$ changes the Uphase at early age, but the $\mathrm{Na}_{2} \mathrm{SO}_{4}$ gradually changes the U-phase to ettringite and high concentration of $\mathrm{Na}_{2} \mathrm{SO}_{4}$ take longer period for the transformation. The U-phase is completely changed to ettringite at 28 days of exposure. The sulphate solution induces portlandite dissolution and it corelates with gypsum formation in the presence of sulphate. Magnesium sulphate solution significantly influences the portlandite dissolution and gypsum formation and it destabilizes the amorphous as well. The dissolved portlandite leads to form brucite when the samples exposed to magnesium sulphate solution.
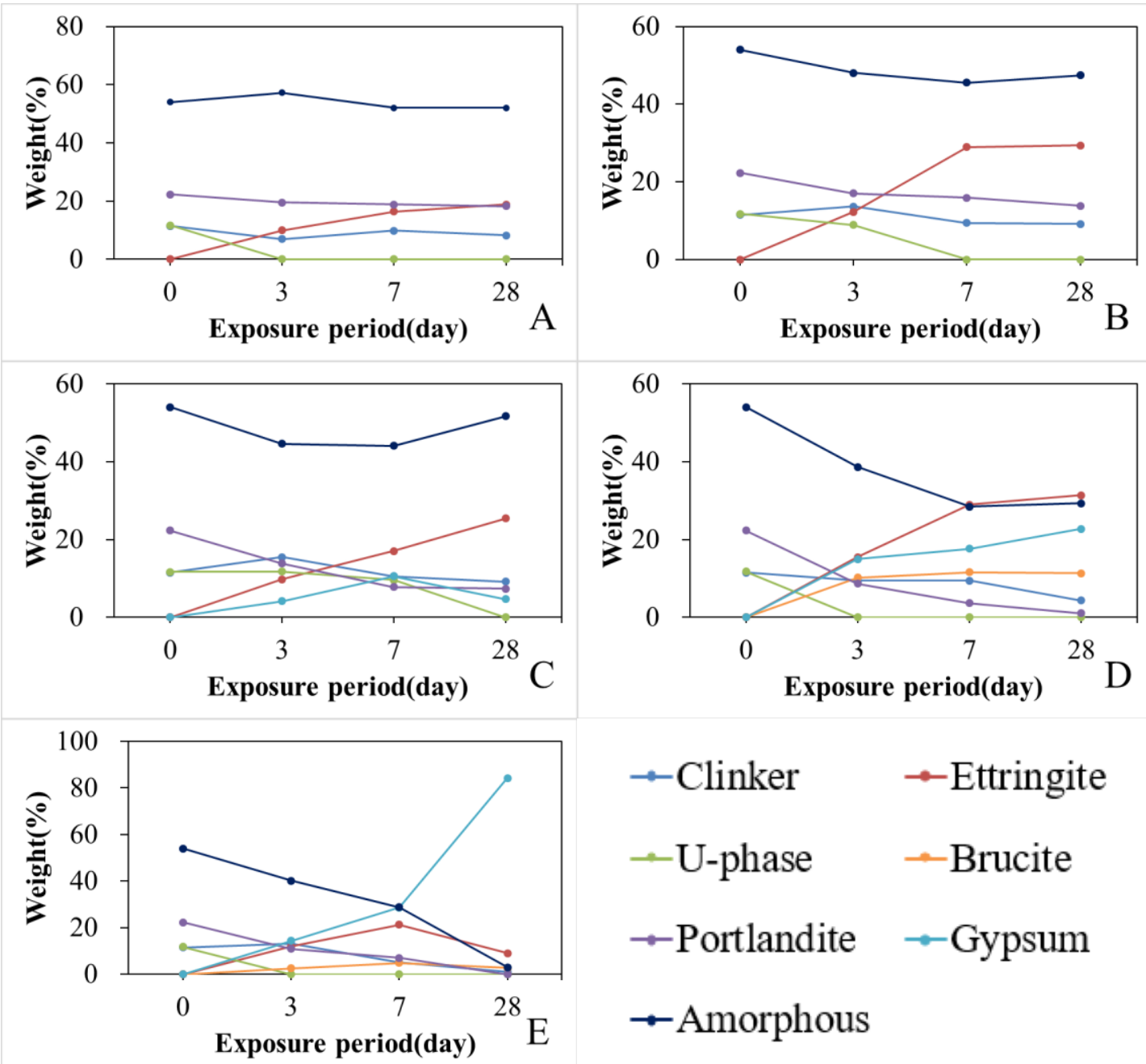

$\rightarrow$ Clinker

-U-phase

$\rightarrow$ Portlandite

$\rightarrow$ Amorphous

Fig. 2. Change of hydration products in Series 1 specimens exposed to A: Water; B:100 $\mathrm{mmol} / \mathrm{L} \mathrm{Na}_{2} \mathrm{SO}_{4} ; \mathrm{C}: 1300 \mathrm{mmol} / \mathrm{L} \mathrm{Na}_{2} \mathrm{SO}_{4} ; \mathrm{D}: 100 \mathrm{mmol} / \mathrm{L} \mathrm{MgSO}_{4} ; \mathrm{E}: 1300 \mathrm{mmol} / \mathrm{L}$ $\mathrm{MgSO}_{4}$

Figure 3 shows phase changes in Series 2 samples exposed to 100 and $1300 \mathrm{mmol} / \mathrm{L}$ $\mathrm{Na}_{2} \mathrm{SO}_{4}$ and $1300 \mathrm{MgSO}_{4}$. A partial replacement of slag affects amounts of phases present in the hydrates samples before it exposed to sulphate solution: lower portlandite and higher U-phase compared to hydrated WPC. The tendency of the phase changes of hydrated slag-blended cement exposed to sulphate solution is similar to WPC, however the initial amount of hydrates influences the behaviour. The relationship between U-phase dissolution and ettringite formation is the same as observed in WPC and it relates to type and concentration of sulphate solution. A lower amount of initial portlandite in slag- 
blended cement limits the formation of brucite when slag-blended cement exposed to magnesium sulphate solution. As observed in WPC, magnesium sulphate solution induces severe degradation to slag-blended cement as well.

The interaction of sodium and magnesium sulphate with hydrated WPC is examined in Series 3 where WPC is hydrated without $\mathrm{Na}_{2} \mathrm{SO}_{4}$. The results of phase change are shown in Fig. 4. Ettringite and gypsum are sulphate-bearing products formed at 28 days of exposure in both sodium and magnesium solution. The formation of U-phase was observed in the samples exposed to sodium sulphate solution at 7 days of exposure and it was changed to ettringite at longer exposure period. As observed in Series 1 and 2, magnesium sulphate solution induces significant degradation, which induces the complete dissolution of portlandite and thus brucite formation.

Based on the results obtained in Series 1-3, the initial U-phase formed during the hydration of cement with sodium sulphate is not stable in water, sodium or magnesium sulphate solution up to $1300 \mathrm{mmol} / \mathrm{L}$. It dissolves and transforms to ettringite during the exposure because the U-phase is in equilibrium at very high concentration of sodium sulphate.
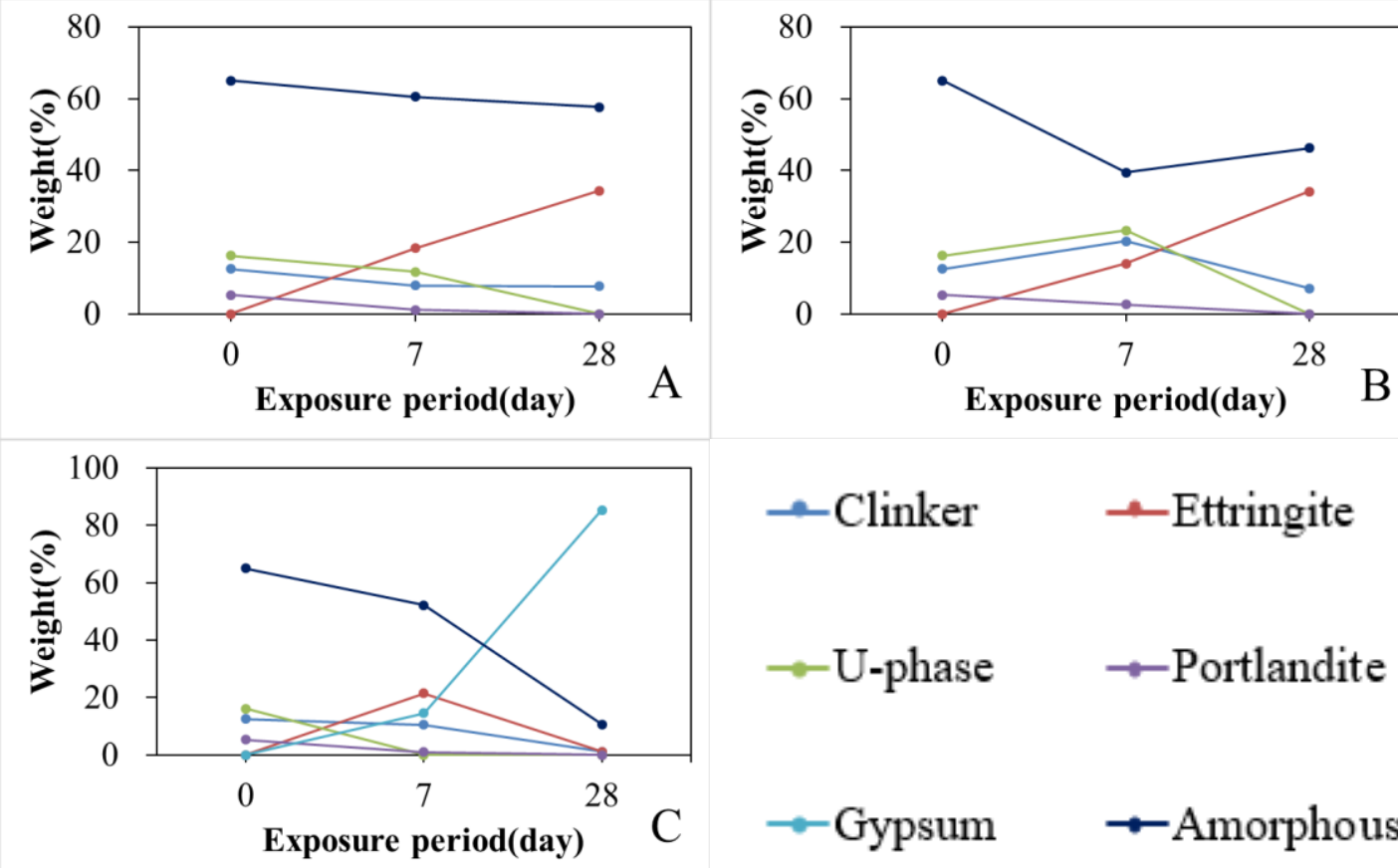

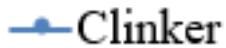

$\rightarrow$ U-phase

Gypsum

\section{-Ettringite} $\rightarrow$ Portlandite

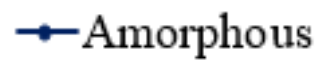

Fig. 3. Change of hydration products in Series 2 specimens exposed to A:100 mmol/L $\mathrm{Na}_{2} \mathrm{SO}_{4} ; \mathrm{B}: 1300 \mathrm{mmol} / \mathrm{L} \mathrm{Na}_{2} \mathrm{SO}_{4} ; \mathrm{C}: 1300 \mathrm{mmol} / \mathrm{L} \mathrm{MgSO}_{4}$
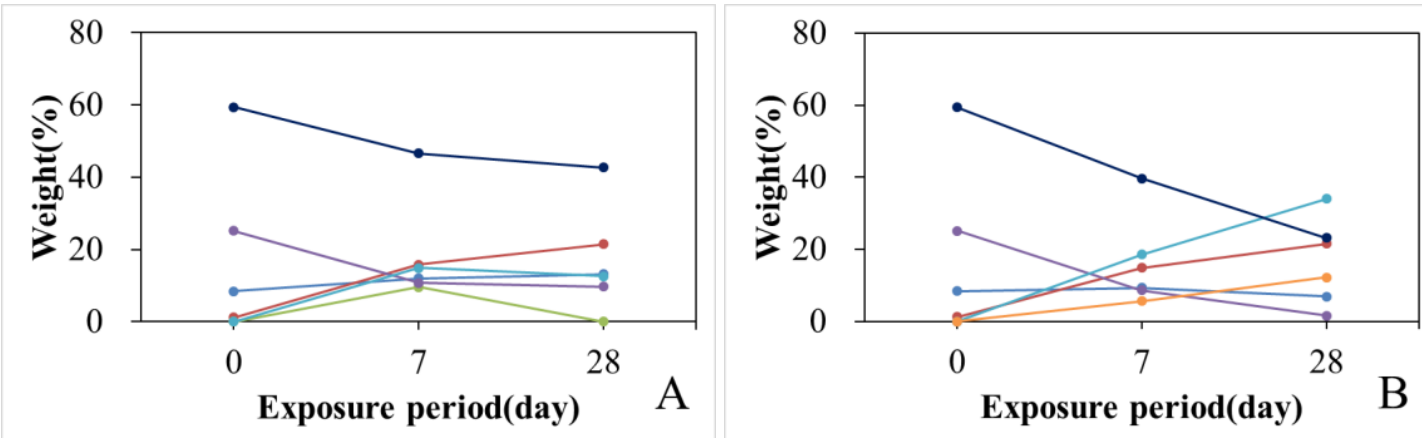

$\rightarrow$ Clinker $\rightarrow$-Ettringite $\rightarrow$-U-phase $\rightarrow$-Brucite $\rightarrow$ Portlandite $\rightarrow$-Gypsum $\rightarrow$-Amorphous 
Fig. 4. Change of hydration products in Series 3 specimens exposed to A:1300 mmol/L $\mathrm{Na}_{2} \mathrm{SO}_{4} ; \mathrm{B}: 1300 \mathrm{mmol} / \mathrm{L} \mathrm{MgSO}_{4}$

\section{Comparison of Experimental Data with Simulation Results}

The phase-equilibrium calculations were carried out for thermodynamic equilibrium between cement hydrates and sulphate solution. Solid products at 28 days of hydrated WPC and its slag-blended case were estimated from the hydration model (Elakneswaran 2016) and used as input parameters for phase-equilibrium calculations. The simulation results were compared with experimental data for the hydrates of Series 1 to 3 exposed to water, and sodium and magnesium sulphate solution for a period of 28 days as the experimental data of longer exposure period was considered for the equilibrium. The simulation results of $\mathrm{C}-\mathrm{S}-\mathrm{H}$ and un-hydrated slag were considered as amorphous. Comparison between model prediction and experimental data is shown in Figs. 5 to 7 . The model rather reproduces the quantitative value of products change during the exposure except U-phase disappearance and ettringite formation. The adopted equilibrium constant value for U-phase (Eq. (1)-(2)) strongly affects its presence or absence in the hydrates. More detail study is needed to estimate the equilibrium constant value of U-phase.
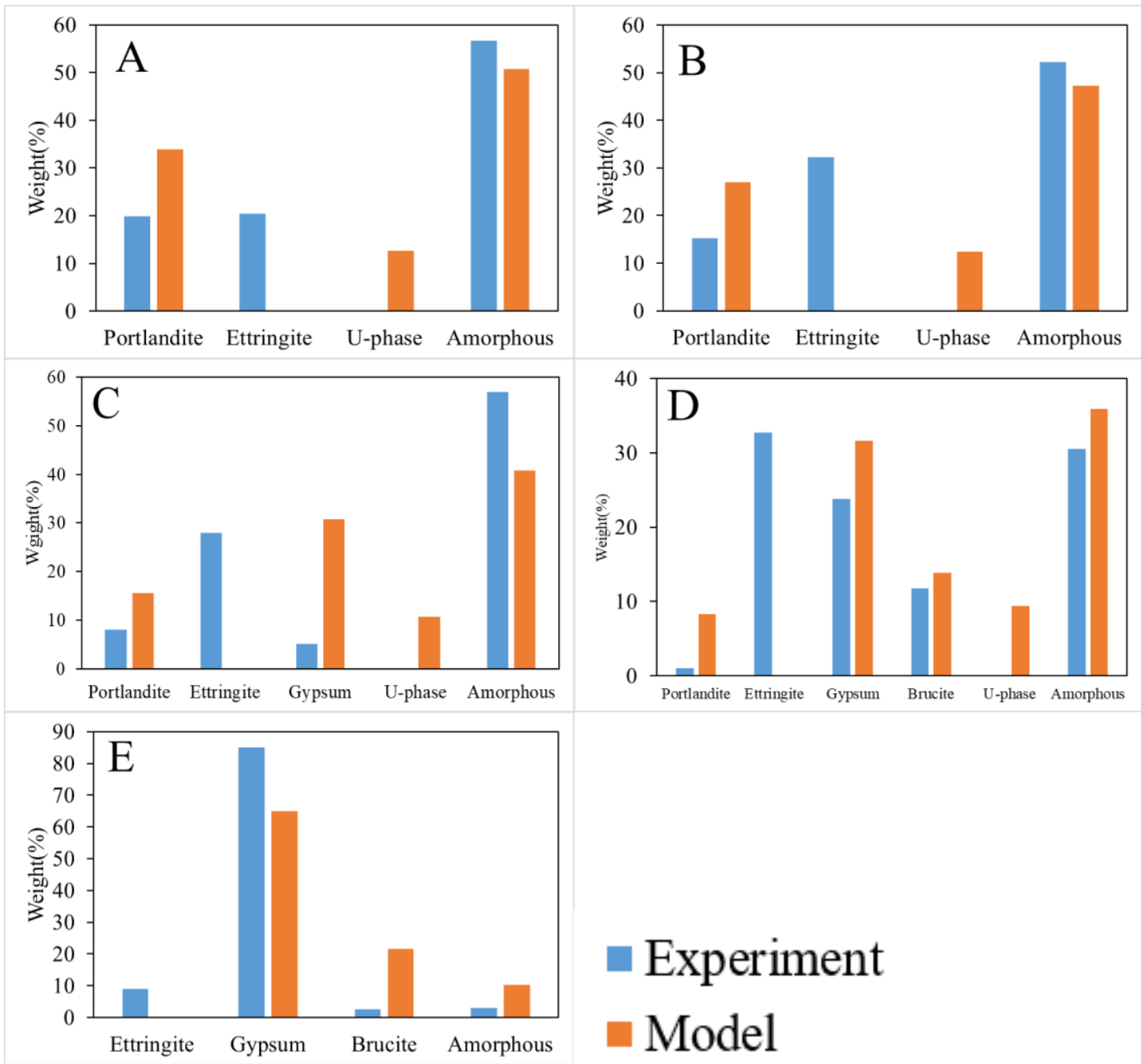

\section{Experiment} Model

Fig. 5. Comparison of predicted phases with experimental data for Series 1 specimens exposed to A: Water; B:100 mmol/L Na $2 \mathrm{SO}_{4} ; \mathrm{C}: 1300 \mathrm{mmol} / \mathrm{L} \mathrm{Na}_{2} \mathrm{SO}_{4} ; \mathrm{D}: 100 \mathrm{mmol} / \mathrm{L}$ $\mathrm{MgSO}_{4} ; \mathrm{E}: 1300 \mathrm{mmol} / \mathrm{L} \mathrm{MgSO}_{4}$ 

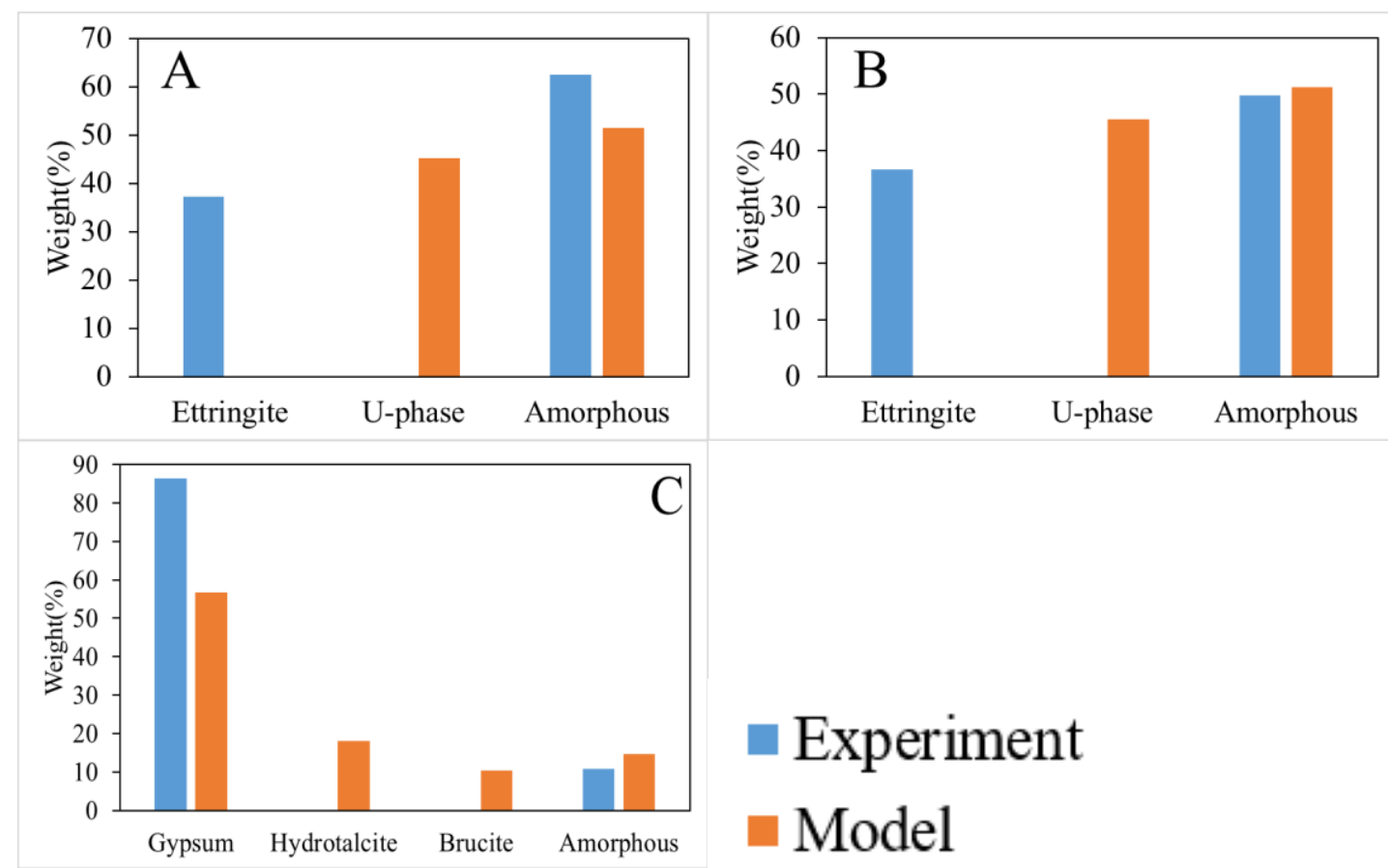

Fig. 6. Comparison of predicted phases with experimental data for Series 2 specimens exposed to A:100 mmol/L Na2 $\mathrm{SO}_{4}$; B:1300 mmol/L Na $2 \mathrm{SO}_{4} ; \mathrm{C}: 1300 \mathrm{mmol} / \mathrm{L} \mathrm{MgSO}_{4}$
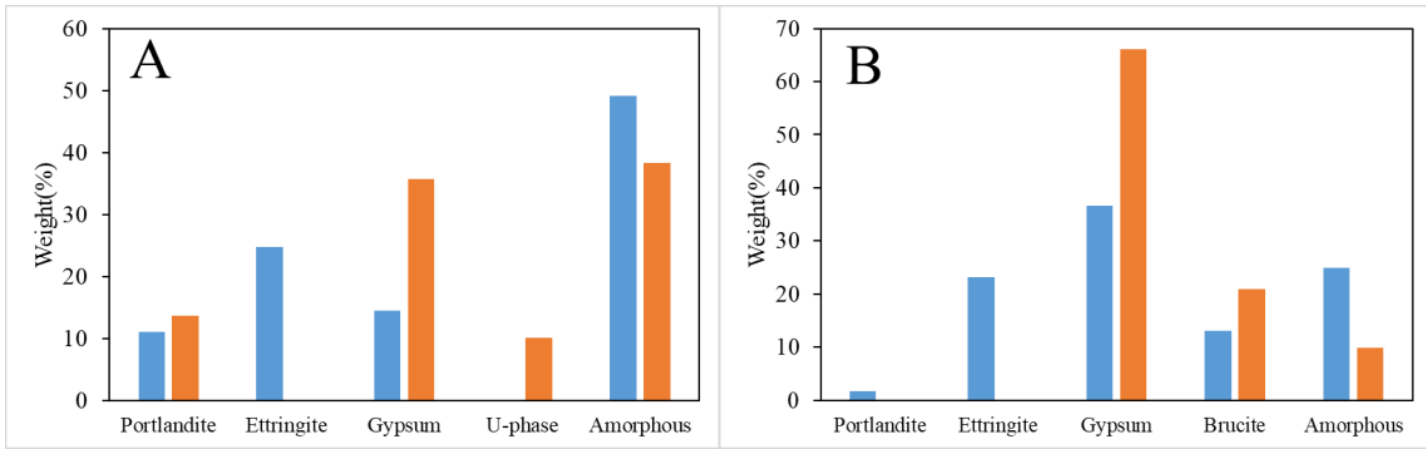

\section{Experiment $\square$ Model}

Fig. 7. Comparison of predicted phases with experimental data for Series 3 specimens exposed to A: $1300 \mathrm{mmol} / \mathrm{L} \mathrm{Na}_{2} \mathrm{SO}_{4}$; B: $1300 \mathrm{mmol} / \mathrm{L} \mathrm{MgSO}_{4}$

\section{CONCLUSION}

The chemical interaction of sulphate ions with cement hydrates formed from the hydration of Portland cement and slag-blended cement with sodium sulphate is studied. The U-phase was identified in both Portland cement and its slag-blended case hydrated with high concentration of sodium sulphate, and the U-phase limits the ettringite formation which was observed in the cement hydrated without sodium sulphate. The U-phase is dissolved and transformed to ettringite as the hydrated cement exposed to water or sulphate solution. The kind of sulphate solution and its concentration affect the stability U-phase and thus ettringite formation. Furthermore, the sulphate solution exposure dissolves the portlandite with a consequent formation of gypsum. Magnesium sulphate solution causes a severe damage to the hydrated cement as compared to sodium sulphate solution. Thermodynamic model was used to predict the phase change during the exposure, and the model rather 
predicts the phase change except U-phase dissolution and ettringite formation.

\section{ACKNOWLEDGEMENTS}

A part of this study financially was supported by JSPS KAKENHI Grant No: $18 \mathrm{~K} 0429708$.

\section{REFERENCES}

Elakneswaran Y et al. (2016), Hydration study of slag-blended cement based on thermodynamic considerations. Construction and Building Materials, 124, pp. 615-625.

Elakeswaran Y et al.,(2018). "Modelling Long-Term Durability Performance of Cementitious Materials under Sodium Sulphate Interaction", Applied Sciences, 8, 2597.

Jean-Baptiste Champenois et al. (2015). "Influence of sodium borate on the early age hydration of calcium sulfoaluminate cement". Cement and Concrete Research, 70, 83-93.

Kajio. T et al. (2018) Characterization of U-Phase and its prediction in cementitious materials, NUWCEM 2018.

$\mathrm{Li}, \mathrm{G}$ et al., (1996). "The U phase formation in cement-based systems containing high amounts of $\mathrm{Na}_{2} \mathrm{SO}_{4}$ ", Cement and Concrete Research, Vol. 26, pp.27-33.

$\mathrm{Li}, \mathrm{G}$ et al., (1996). "Synthesis of the $\mathrm{U}$ phase $\left(4 \mathrm{CaO} \cdot 0.9 \mathrm{Al}_{2} \mathrm{O}_{3} \cdot 1.1 \mathrm{SO}_{3} \cdot 0.5 \mathrm{Na}_{2} \mathrm{O} \cdot 16 \mathrm{H}_{2} \mathrm{O}\right)$ ", Cement and Concrete Research, Vol, 27, No.1, pp.7-13.

Lothenbach B. et al. (2008). "Thermodynamic modelling of the effect of temperature on the hydration and porosity of Portland cement". Cement and Concrete Research, 38, 1-18.

Myers R.J. et al. (2014). “A thermodynamic model for C-(N-)S-H gel: CNASH_ss. Dervation and validation". Cement and Concrete Research, 66, 27-47.

Owaki, E.; Niwase, K.; Akatsuka, M.; Kudo, J. Effect of curing temperature on cement paste containing sodium sulphate. JSCE Ann. Meet. 2012, 67, 57-58.

Parkhust D.L. et al. (1999). "A computer program for speciation, batch-reaction, onedimensional transport and inverse geochemical calculations". USGS Report.

Scrivener, K.; Skalny, J. International RILEM Workshop on Internal Sulfate Attack and Delayed Ettringite Formation. Mater. Struct. 2004, 37, 71-72. [CrossRef] 